\title{
Schistosomiasis Manifesting as a Rectum Polyp in Nigeria
}

\author{
Wilson I. B. Onuigbo ${ }^{1}$, Chineme M. Anyaeze ${ }^{2}$ \\ ${ }^{1}$ Medical Foundation \& Clinic, Enugu, Nigeria \\ ${ }^{2}$ Mater Hospital, Afikpo, Nigeria \\ *Corresponding Author: Wilson I. B. Onuigbo, Medical Foundation \& Clinic, Enugu, Nigeria

\begin{abstract}
Schistosomiasis is a rare worm disease with variable choice sites of presentation. Recent publications include involvement of the colon and rectum in countries as diverse as Lebanon, Egypt and USA, where the source was ascribed to "The large shift of population from Puerto Rico, where the parasite is endemic." It is usually benign but malignancy may supervene. Therefore, this paper is devoted to a benign case seen in Nigeria in respect of the rectum.
\end{abstract}

Keywords: Schistosomiasis, worm disease, rare sites, rectum, Nigeria.

\section{INTRODUCTION}

Schistosomiasis is a peculiar worm disease found in different parts of the world (1). In this respect, migration plays an important part, e.g., an Ethiopian woman living in Lebanon (2) and those patients from Puerto Rico, "where the parasite is endemic," but were treated in USA (3). Incidentally, the available single cases of intestinal infestation by schistosomes were recorded in terms of "polyp" formation $(2,3)$. Therefore, our paper contributes this type of infestation.

\section{CASE Report}

AG, a 85-year-old woman of the Igbo ethnic group (4), came to the Mater Hospital, Afikpo, with the complaint of rectal bleeding as well as some mucus and pain on defecation of 3 weeks duration. The junior author (CMA) examined her and found a pedunculated rectal polyp at 4 o'clock position. The question of malignancy was entertained and excision was carried out. This specimen was submitted to the senior author (WIBO).

Inspection revealed an irregularly surfaced polyp measuring $2.5 \mathrm{~cm}$ across, the peduncle being $2.0 \mathrm{~cm}$ long. On section, there was a hemorrhagic growth. Microscopy showed the polyp to be benign and inflamed. There were scattered terminal-spined ova characteristic of schistosomiasis of the haematobium type. Recovery proved to be uneventful.

\section{DISCUSSION}

Previously, schistosomiasis was reported in our local community with reference to the appendix (5), urinary bladder (6), ovary (7), and childhood perineum in which it was mistaken as being due to sexual abuse (8). In their review and case series, Alam and associates (9) collected up to 32 cases reported from the intestinal tract but without further specification.

Schistosomiasis may be associated with malignancy. Our case did not have this problem. Another series of 32 cases from China (10) concluded that "Chronic schistosomiasis infestation has a probable etiological role in promoting genesis of colorectal neoplasm." Fortunately, the present patient reported promptly in accordance with the prevailing community health education standards (11).

\section{REFERENCES}

[1] Parry EHO. Principles of Medicine in Africa. Oxford University Press, 1976; p. 195.

[2] Issa I, Osman M, Aftimos G. Schistosomiasis manifesting as a colon polyp: a case report. J Med Case Rep, 2014; 8: 331. doi: 10.1186/1752-1947-8-331.

[3] Elbaz T, Esmat G. Hepatic and intestinal shistosomiasis: Review. J Advanced Res, 2013; 4(5): 445-452.

[4] Basden GT. Niger Ibos. Cass, London 1966.

[5] Onuigbo WIB. Appendiceal schistosomiasis: method for classifying oviposition and inflammation. Dis Colon Rect, 1985; 28:397398. 
[6] Onuigbo WIB. Carcinoma of urinary bladder in a region of low schistosomiasis. J Coll Med, 2005; 10:3-5.

[7] Onuigbo WIB, Twomey D. Schistosomiasis of ovarian thecoma. Med J Zambia, 1978; 12:2728.

[8] Onuigbo WIB, Anyaeze CM, Ozumba BC. Sexual abuse simulated by schistosomiasis. Child Abuse Neglect, 1999; 23:947-949.

[9] Alam K, Maheshwari V, Jain A, et al. Schistosomiasis: A case series, with review of literature. Internet J Infect Dis, 2008; 7(1).
[10] Liu W, Zeng H, Wang Q, et al. Schistosomiasis combined with colorectal carcinoma diagnosed based on endoscopic findings and clninicopathological characteristics: A report on 32 cases. Asian Pac J Cancer Prev, 2013; 14(8): 4839-4842.

[11] Onuigbo WIB. Albino skin cancer will end if a community's cancer surveillance program is successful. J Hlth Edu Res Dev, 2016; 4: 161. doi: $\quad 10.4172 / 2380-5439.1000161 .4(3): 00123$. DOI:10.15406/jcpcr.2016.04.00123.

Citation: Wilson I. B. O, Chineme M. A. Schistosomiasis Manifesting as a Rectum Polyp in Nigeria. International Journal of Research Studies in Medical and Health Sciences. 2017;2(3):11-12.

Copyright: (C) 2017 Wilson I. B. O, et al. This is an open-access article distributed under the terms of the Creative Commons Attribution License, which permits unrestricted use, distribution, and reproduction in any medium, provided the original author and source are credited. 